\title{
Improving the electrical performance of resistive switching memory using doping technology
}

\author{
WANG Yan ${ }^{1,2}$ LIU $^{2}{ }^{2}$, LÜ HangBing ${ }^{2}$, LONG ShiBing ${ }^{2}$, WANG Wei ${ }^{1}$, LI YingTao ${ }^{1,2}$, \\ ZHANG Sen ${ }^{2}$, LIAN WenTai ${ }^{2}$, YANG JianHong ${ }^{1} \&$ LIU Ming ${ }^{2 *}$ \\ ${ }^{1}$ College of Physical Science and Technology, Lanzhou University, Lanzhou 730000, China; \\ ${ }^{2}$ Laboratory of Nano-Fabrication and Novel Device Integration, Institute of Microelectronics, Chinese Academy of Sciences, Beijing 100029, \\ China
}

Received July 7, 2011; accepted November 21, 2011

\begin{abstract}
In this paper, improvements of resistive random access memory (RRAM) using doping technology are summarized and analyzed. Based on a $\mathrm{Cu} / \mathrm{ZrO}_{2} / \mathrm{Pt}$ device, three doping technologies with $\mathrm{Ti}$ ions, $\mathrm{Cu}$, and $\mathrm{Cu}$ nanocrystal, respectively, are adopted in the experiments. Compared to an undoped device, improvements focus on four points: eliminating the electroforming process, reducing operation voltage, improving electrical uniformity, and increasing device yield. In addition, thermal stability of the high resistance state and better retention are also achieved by the doping technology. We demonstrate that doping technology is an effective way of improving the electrical performance of RRAM.
\end{abstract}

non-volatile memory, resistive random access memory (RRAM), doping technology

Citation: Wang Y, Liu Q, LÜ H B, et al. Improving the electrical performance of resistive switching memory using doping technology. Chin Sci Bull, 2012, 57: 1235-1240, doi: 10.1007/s11434-011-4930-0

How far floating gate based memory can extend and what the further direction of next generation memory is, are two research questions that have attracted extensive attention and concern. To solve the shortcomings of conventional memories, several new emerging memories, including magnetic random access memory (MRAM), ferroelectric random access memory (FRAM), phase-change random access memory (PRAM), and resistance random access memory (RRAM), have been studied as candidates for future memories [1]. Of these candidates, RRAM devices based on binary metal oxide (BMO) have received considerable research attention because of their advantages of simple device structure, high density, excellent scalability, fast switching speed, low energy consumption, and compatibility with CMOS technology [2].

In general, RRAM has a sandwich structure of metal-insulator-metal. The "metal" here denotes a material with

*Corresponding author (email: liuming@ime.ac.cn) good electrical conductivity [3], where $\mathrm{Cu}, \mathrm{Ag}, \mathrm{Pt}, \mathrm{Ti}$, and TiN are the materials most frequently used as electrodes in this capacitor-like structure [4-8]. Several BMO materials such as $\mathrm{ZrO}_{2}$ [9], $\mathrm{HfO}_{2}$ [4,8], $\mathrm{TiO}_{x}$ [10], $\mathrm{ZnO}_{2}$ [5], $\mathrm{NiO}$ [11], $\mathrm{CeO}_{x}$ [12], $\mathrm{Ta}_{2} \mathrm{O}_{5}$ [13], $\mathrm{CuO}_{x}$ [14], and $\mathrm{WO}_{x}$ [15] have been reported as the insulator layer in RRAM. Under an appropriate electric stimulus, the resistance of the insulator layer can be switched between a high resistance state (HRS) and a low resistance state (LRS). The memory effect is realized by the different resistance states. Although the mechanisms responsible for the resistive switching behaviors in different materials are still being debated intensely, the critical role of defects and impurities in resistive switching has been recognized. Unfortunately, the intrinsic defects (i.e., dislocation, grain boundary, ions, or vacancy) in BMO films are inhomogeneously and nonuniformly distributed and difficult to control. RRAM devices with pure BMO films often exhibit unfavorable memory performance, i.e., low device yield, high operation voltage, low uniformity, and poor device stability, 
which hampers their application in industry [16].

Several research groups have adopted doping technology as an effective method for solving above problems. It has been demonstrated that the performance of BMO-based RRAM devices can be greatly improved by intentionally introducing homogenous impurities in the BMO films [16-24]. In this paper, we discuss the effect of doping technology on the resistive switching characteristics of RRAM devices. Undoped $\mathrm{Cu} / \mathrm{ZrO}_{2} / \mathrm{Pt}$ devices are fabricated for comparison, while three types of doping technology including $\mathrm{Ti}, \mathrm{Cu}$, and $\mathrm{Cu}$ nanocrystal (NC) in the $\mathrm{Cu} / \mathrm{ZrO}_{2} /$ Pt are referred to in our discussion.

$\mathrm{Ti}$ impurities are doped in the $\mathrm{ZrO}_{2}$ films using the ion implantation method, while the $\mathrm{Cu}$ and $\mathrm{Cu}$ NC impurities are introduced using a thermal diffusion method. The detailed fabrication processes of the $\mathrm{Cu} / \mathrm{ZrO}_{2}: \mathrm{Ti} / \mathrm{Pt}$, $\mathrm{Cu} / \mathrm{ZrO}_{2}: \mathrm{Cu} / \mathrm{Pt}$, and $\mathrm{Cu} / \mathrm{ZrO}_{2}: \mathrm{Cu} \mathrm{NC} / \mathrm{Pt}$ devices have been described, respectively, in our previous papers [17,23,24]. The control samples $\left(\mathrm{Cu} / \mathrm{ZrO}_{2} / \mathrm{Pt}\right)$ without doping impurities are simultaneously fabricated to investigate the impact of doping impurities on the resistive switching behavior. The electrical parameters for these devices are measured with the Keithley 4200 semiconductor characterization system and Agilent 81110A pulse pattern generator. For the electrical measurements, the bias polarity is defined with reference to the bottom Pt electrode.

\section{Characteristics of undoped-BMO-based RRAM devices}

Figure 1 shows 10 cycles of the current-voltage $(I-V)$ curves of the $\mathrm{Cu} / \mathrm{ZrO}_{2} / \mathrm{Pt}$ device under DC voltage sweep. As can be seen from this figure, the resistive switching characteristics of the undoped RRAM device exhibit two weaknesses. (i) An electroforming process with a high voltage $(\sim 10 \mathrm{~V})$ is needed to trigger resistive switching behaviors. In this process, a $1 \mathrm{~mA}$ current compliance is used to prevent the

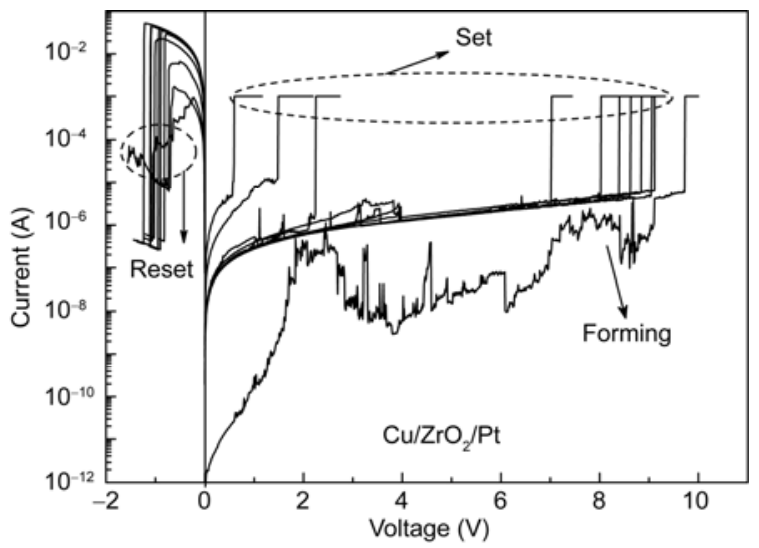

Figure 1 Reproducibility of the resistive switching (10 cycles) of the $\mathrm{Cu} / \mathrm{ZrO}_{2} / \mathrm{Pt}$ device under DC voltage sweep. Here, the cell size is $100 \mu \mathrm{m} \times$ $100 \mu \mathrm{m}$ and the $\mathrm{ZrO}_{2}$ thickness is $70 \mathrm{~nm}$.
BMO films from hard breakdown. (ii) A wide distribution of the resistive switching parameter is shown in the undoped RRAM devices. The $V_{\text {Set }}$ and $V_{\text {Reset }}$ are, respectively, the threshold voltages from the HRS to the LRS, and vice versa. For the undoped $\mathrm{Cu} / \mathrm{ZrO}_{2} / \mathrm{Pt}$ device, the distributions of $V_{\text {Set }}$ and $R_{\mathrm{HRS}}$ have wide ranges. A high electroforming voltage and poor electrical uniformity are also observed in other undoped-BMO-based RRAM devices, such as TiN/ $\mathrm{HfO}_{2} / \mathrm{Pt}, \mathrm{Pt} / \mathrm{TiO}_{2} / \mathrm{Pt}$, and $\mathrm{Pt} / \mathrm{NiO} / \mathrm{Pt}$ [25-27].

Additionally, low device yield is also observed in the undoped-BMO-based RRAM devices. For example, only about $40 \%$ of the cells of the $\mathrm{Cu} / \mathrm{ZrO}_{2} / \mathrm{Pt}$ devices show the repetitive resistive switching phenomenon. For real application, these weaknesses of undoped-BMO-based RRAM devices must be well controlled.

\section{Improving resistive switching performance with doping technology}

Before discussing the doping effect, we first address the conceivable resistive switching mechanism in BMO-based RRAM. Recent studies have shown that the resistive switching behavior in a BMO-based RRAM device is mainly dominated by the formation/rupture of the conductive filaments inside the BMO layer [18]. The conductive filament is formed by the percolation of defects, such as the migration of metal ions or oxygen vacancies [3]. These defects may come from decomposition of the function materials themselves or diffusion from the electrode materials. However, the generation of these defects in pure BMO films requires a higher voltage. The quality of the films degrades easily under high electrical stimulus, resulting in the poor resistive switching characteristics mentioned above. According to the analysis, if reasonable defects can be introduced into the proper positions in BMO films, high voltage may no longer be necessary and the resistive switching performance can be improved.

\subsection{Eliminating the electroforming process and reduc- ing operation voltage}

The electroforming operation can induce enough defects (i.e., charge traps, movable ions, or vacancies) in BMO films because of the high electrical voltage. The process is similar to soft-breakdown in an oxide [28]. Under high electrical fields, the induced defects form a local conducting filament between the bottom and top electrodes, resulting in a change in the resistive switching from the HRS to the LRS. However, the high voltage not only degrades the materials reliability, but also complicates the RRAM circuit's design. Thus, the excessive voltage required is undesirable.

By doping proper impurities, the electroforming process can be eliminated and the operation voltage can also be re duced. The $I-V$ curve of the Ti doped $\mathrm{ZrO}_{2}$ device is shown 
in Figure 2, where the required voltage of the first Set operation is equal to that of the following Set process. Furthermore, the maximum operation voltage of the $\mathrm{Cu} / \mathrm{ZrO}_{2} / \mathrm{Pt}$ is reduced from 10 to $3 \mathrm{~V}$ by doping Ti impurities. It is worth to note that the $\mathrm{Cu} / \mathrm{ZrO}_{2}: \mathrm{Cu} / \mathrm{Pt}$ and $\mathrm{Cu} / \mathrm{ZrO}_{2}: \mathrm{Cu} \mathrm{NC} / \mathrm{Pt}$ devices exhibit a similar phenomenon $[17,23]$. The doping induced forming-free phenomenon has also been observed in other BMO-based RRAMs by other researchers. For example, Gao et al. [28] reported that the average forming voltage of the $\mathrm{TiN} / \mathrm{HfO}_{2} / \mathrm{Pt}$ device decreased from 7.82 to $2.71 \mathrm{~V}$ by doping $\mathrm{Al}$ in the $\mathrm{HfO}_{2}$ films.

Figure 3(a) and (b) shows the typical $I-V$ characteristics of the $\mathrm{Cu} / \mathrm{ZrO}_{2}: \mathrm{Cu} / \mathrm{Pt}$ and $\mathrm{Cu} / \mathrm{ZrO}_{2}: \mathrm{Cu} \mathrm{NC} / \mathrm{Pt}$ devices, respectively. Both devices exhibit unique nonpolar resistive switching behavior (the Set and Reset operation can be achieved under negative and positive voltages). Different from the $\mathrm{Cu} / \mathrm{ZrO}_{2}: \mathrm{Cu} / \mathrm{Pt}$ device, the $\mathrm{Cu} / \mathrm{ZrO}_{2}: \mathrm{Cu} \mathrm{NC} / \mathrm{Pt}$ device exhibits a lower positive Set voltage (the $V_{\text {Set }}$ decreased from $\sim 3$ to $\sim 1 \mathrm{~V}$ ). The difference between the two devices can be attributed to the different doping processes. The $\mathrm{Cu}$ NC doping process not only supplies more metal ions, but also enhances the electrical field around the $\mathrm{Cu}$ $\mathrm{NC}$ located within the $\mathrm{ZrO}_{2}$ matrix. The strengthening electrical field can accelerate the migration velocity of $\mathrm{Cu}$ ions and reduce the required voltage to form the conductive filaments [25].

\subsection{Improving electrical uniformity}

In general, large variations in switching voltages and resistance states are shown in undoped-BMO-based RRAM devices, as can be seen in Figure 1. The poor uniformity not only reduces the stability of the device, but also enhances the complexity of the peripheral circuit for read/write operations. In general, the nonuniformity of the switching parameters is related to the random nature of the nucleation/growth of the conductive filament (CF) [3]. This makes it difficult to form the $\mathrm{CF}$ along the same path in repetitive switching cycles.

Compared to the $\mathrm{Cu} / \mathrm{ZrO}_{2} / \mathrm{Pt}$ device, the Ti doped device shows a more stable Set process, as shown in Figure 2. Further evidence verifying this conclusion is given by the statistical data. As shown in Figure 4, the average values of $V_{\text {Set }}$ and $V_{\text {Reset }}$ for the $\mathrm{Cu} / \mathrm{ZrO}_{2}: \mathrm{Ti} / \mathrm{Pt}$ device are 1.43 and $-0.66 \mathrm{~V}$, respectively, which are lower than the values for the $\mathrm{Cu} / \mathrm{ZrO}_{2} / \mathrm{Pt}$ device $(5.31$ and $-0.94 \mathrm{~V}$, respectively). Furthermore, the standard deviation of $V_{\text {Set }}$ is reduced from 3.45 to $0.78 \mathrm{~V}$ after doping $\mathrm{Ti}$ ions. This indicates that the dispersion of $V_{\text {Set }}$ for the $\mathrm{Cu} / \mathrm{ZrO}_{2}$ :Ti/Pt device is obviously reduced when compared with the $\mathrm{Cu} / \mathrm{ZrO}_{2} / \mathrm{Pt}$ device. The resistance states in 50 cycles of the $\mathrm{Cu} / \mathrm{ZrO}_{2} / \mathrm{Pt}$ and $\mathrm{Cu} / \mathrm{ZrO}_{2}: \mathrm{Ti} / \mathrm{Pt}$ devices are shown in Figure 5. After doping Ti ions, the fluctuation in $R_{H R S}$ is reduced from $10^{4}$ to 10 times. This proves that the $R_{H R S}$ of the $\mathrm{Cu} / \mathrm{ZrO}_{2}: \mathrm{Ti} / \mathrm{Pt}$ device is more stable than that of the $\mathrm{Cu} / \mathrm{ZrO}_{2} / \mathrm{Pt}$ device. In addition, the $\mathrm{Cu} / \mathrm{ZrO}_{2}: \mathrm{Cu} / \mathrm{Pt}$ and $\mathrm{Cu} / \mathrm{ZrO}_{2}: \mathrm{Cu} \mathrm{NC} / \mathrm{Pt}$ devices also show tight distribution of the resistive switching parameters $[17,23]$.

Previously, improvement in the electrical uniformity of

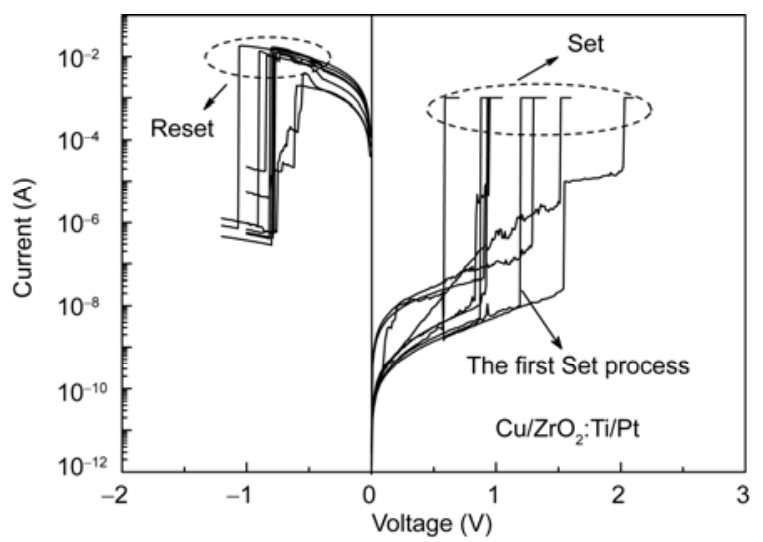

Figure 2 Reproducibility of the resistive switching (10 cycles) of the $\mathrm{Cu} / \mathrm{ZrO}_{2}: \mathrm{Ti} / \mathrm{Pt}$ device under DC voltage sweep. The cell size is $100 \mu \mathrm{m}$ $\times 100 \mu \mathrm{m}$ and the $\mathrm{ZrO}_{2}$-thinkness is $70 \mathrm{~nm}$.
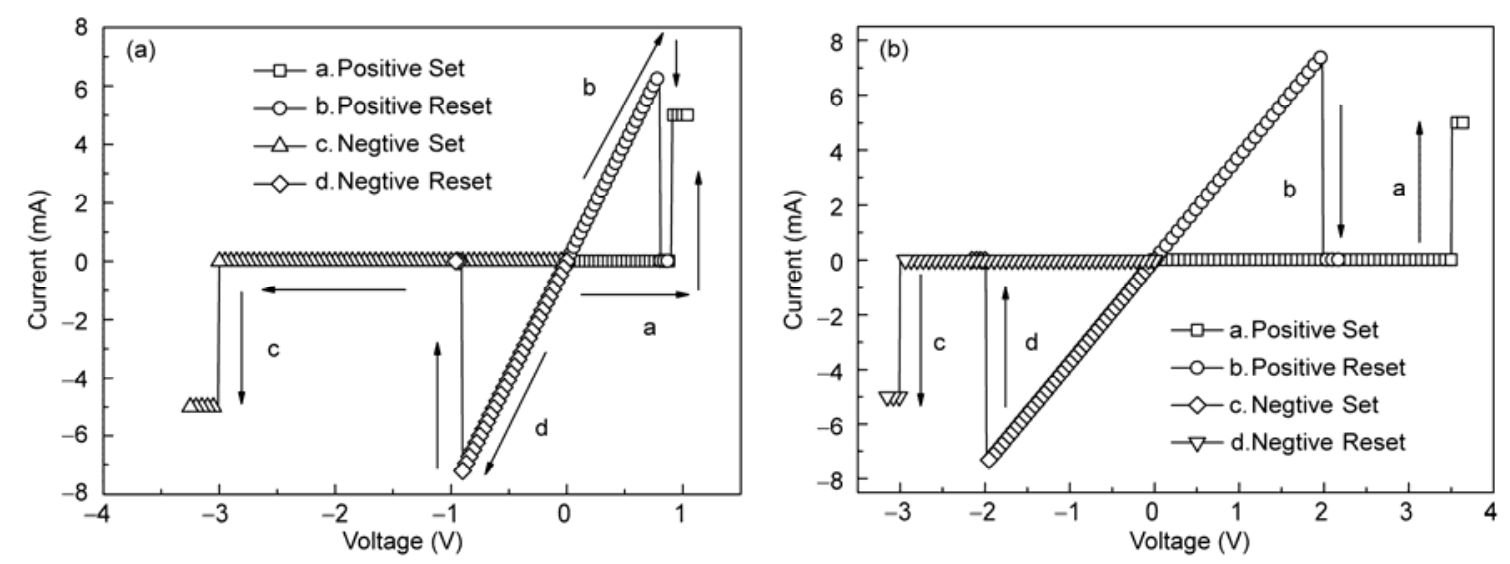

Figure 3 (a) Typical asymmetric nonpolar $I-V$ switching behavior of the $\mathrm{Cu} / \mathrm{ZrO}_{2}: \mathrm{Cu} \mathrm{NC} / \mathrm{Pt}$ device, and (b) typical symmetric nonpolar $I-V$ switching behavior of the $\mathrm{Cu} / \mathrm{ZrO}_{2}: \mathrm{Cu} / \mathrm{Pt}$ device. The cell size of both devices is $3 \mu \mathrm{m} \times 3 \mu \mathrm{m}$ and the thickness of $\mathrm{ZrO}_{2}$ is $40 \mathrm{~nm}$. 


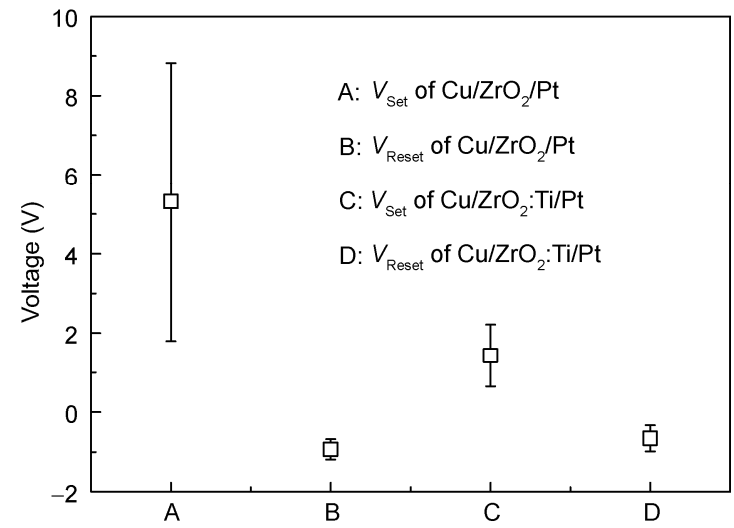

Figure 4 Variations in operating voltage in $\mathrm{Cu} / \mathrm{ZrO}_{2} / \mathrm{Pt}$ and $\mathrm{Cu} /$ $\mathrm{ZrO}_{2}: \mathrm{Ti} / \mathrm{Pt}$ devices.

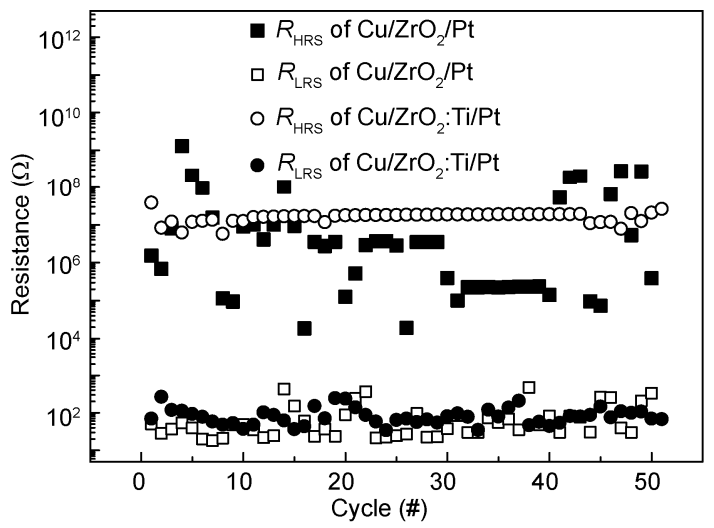

Figure 5 Distribution of $R_{\mathrm{HRS}}$ and $R_{\mathrm{LRS}}$ in the $\mathrm{Cu} / \mathrm{ZrO}_{2} / \mathrm{Pt}$ and $\mathrm{Cu} / \mathrm{ZrO}_{2}: \mathrm{Ti} / \mathrm{Pt}$ devices.

impurities doping in RRAM device has been demonstrated by a variety of studies [17-30]. However, why doping impurities improve the electrical uniformity of the RRAM device is still unclear. A general hypothesis is stated as follows: the conductive filaments are easily formed/ruptured near the impurities doped location. This reduces the randomness of the $\mathrm{CF}$ formation/rupture process and improves the uniformity of the resistive switching properties. In our recent work [18], we obtained high resolution transmission electron microscopy images of conductive filaments in the $\mathrm{Ag} / \mathrm{ZrO}_{2} / \mathrm{Cu} \mathrm{NC} / \mathrm{Pt}$ device. These images show that the growth location and orientation of $\mathrm{CFs}$ can be well controlled by the $\mathrm{Cu} \mathrm{NC}$ dopant. According to the electrical field simulation, the $\mathrm{Cu}$ NC plays a critical role in enhancing the local electrical field. During the Set process, more metal ions converge around the $\mathrm{Cu} \mathrm{NC}$ location under a higher local voltage. So the $\mathrm{CF}$ grows easily at the location of the NC. Thus, CFs are easily formed, ruptured, and reformed along the same paths in repetitive switching cycles, resulting in a substantial improvement in the electrical uniformity. For other types of doping impurities, further research is needed to investigate the underlying physical mechanism.

\subsection{Increasing device yield}

For actual application, device yield (percentage of working cells) is a critical parameter in the memory array. Unfortunately, low device yields are frequently shown in undoped-BMO-based RRAM devices [16,24]. There are two possible reasons for this. One is the electroforming operation, which is needed to activate the resistive switching behavior in undoped devices. During the forming process, the local region of the BMO film may be broken down under high voltage. Another is the randomness of the intrinsic defects in the undoped BMO film. A large variation in the intrinsic defects leads to unstable resistive switching behavior. By using homogeneous and uniform doping, the defects in the BMO film can be well controlled and the device yield is also improved. As can be seen from Figure 6, the device yield of the $\mathrm{Cu} / \mathrm{ZrO}_{2} / \mathrm{Pt}$ device is greatly improved by doping $\mathrm{Ti}, \mathrm{Cu}$, and $\mathrm{Cu} \mathrm{NC}$. After using doping technology, the device yield of RRAM devices increases to almost $100 \%$. Similar results were also reported by Lee et al. [29] in the $\mathrm{Al}$ doped $\mathrm{ZnO}, \mathrm{Cu}$ doped $\mathrm{MoO}_{x}$ and $\mathrm{Cu}$ doped $\mathrm{Al}_{2} \mathrm{O}_{3}$ devices.

\subsection{Improving other memory performance}

Other important memory characteristics of undoped RRAM devices may also be modulated by doping impurities. Recently, Jung et al. demonstrated that Li-doping $\mathrm{NiO}$ could improve the thermal stability of the HRS. The Li doped device showed a much better retention property and stable Set/Reset operation [31]. Recently, Wang et al. reported that the retention characteristics of both resistive states in the $\mathrm{CuO}_{x}$-based RRAM can be significantly improved by doping $\mathrm{Si}$ impurities. Based on a first principles calculation, they suggested that the activation energy of $\mathrm{Cu}$ vacancy migration in $\mathrm{Cu}_{x} \mathrm{Si}_{y} \mathrm{O}$ increased more than that in $\mathrm{Cu}_{x} \mathrm{O}$, resulting in the good retention characteristics [32]. In our previous work, we demonstrated that the storage window (defined as the ratio of $R_{\mathrm{HRS}} / R_{\mathrm{LRS}}$ ) of the $\mathrm{ZrO}_{2}$ film can

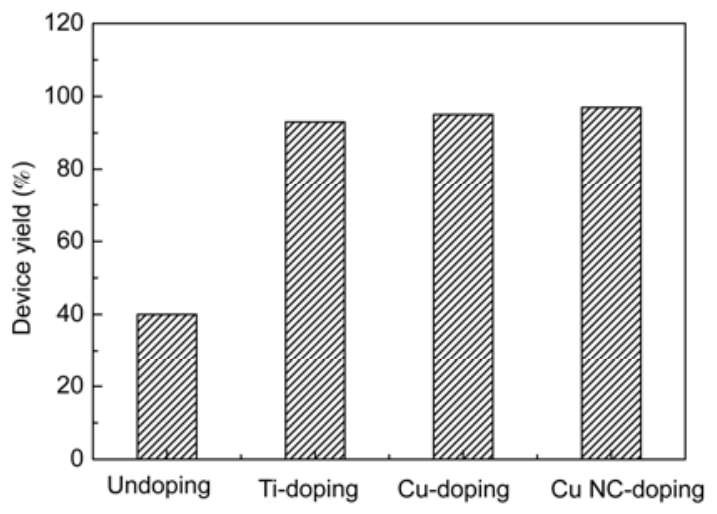

Figure 6 Device yield of the $\mathrm{Cu} / \mathrm{ZrO}_{2} / \mathrm{Pt}, \mathrm{Cu} / \mathrm{ZrO}_{2}: \mathrm{Ti} / \mathrm{Pt}, \mathrm{Cu} / \mathrm{ZrO}_{2}: \mathrm{Cu} / \mathrm{Pt}$, and $\mathrm{Cu} / \mathrm{ZrO}_{2}: \mathrm{Cu} \mathrm{NC} / \mathrm{Pt}$ devices. 
Table 1 Resistive switching characteristics of the undoped and doped devices

\begin{tabular}{|c|c|c|c|c|c|c|c|}
\hline Device structure & Yield (\%) & Forming process & $V_{\mathrm{Set}}(\mathrm{V})$ & $V_{\text {Reset }}(\mathrm{V})$ & $R_{\mathrm{HRS}} / R_{\mathrm{LRS}}$ ratio & Retention (s) & Switching polarity \\
\hline $\mathrm{Cu} / \mathrm{ZrO}_{2} / \mathrm{Pt}$ & $<40$ & Yes & $0.5-10$ & $-0.5--1.5$ & $>10^{4}$ & - & Bipolar \\
\hline $\mathrm{Cu} / \mathrm{ZrO}_{2}: \mathrm{Cu} / \mathrm{Pt}[9]$ & $\sim 100$ & No & $2.1-3.6$ & $0.8-1.5$ & $\sim 10^{6}$ & $>10^{4}$ & Nonpolar \\
\hline $\mathrm{Cu} / \mathrm{ZrO}_{2}: \mathrm{Au} / \mathrm{Pt}[33]$ & $\sim 100$ & No & $2-5$ & $0.5-1.2$ & $>10^{4}$ & $>10^{6}$ & Nonpolar \\
\hline $\mathrm{Cu} / \mathrm{ZrO}_{2}: \mathrm{Ti} / \mathrm{Pt}[24]$ & $\sim 100$ & No & $1-4$ & $-0.5--1.5$ & $>10^{4}$ & $>10^{7}$ & Bipolar \\
\hline $\mathrm{Au} / \mathrm{ZrO}_{2}: \mathrm{Au} / \mathrm{Pt}[16]$ & $\sim 5$ & - & - & - & - & - & Bipolar \\
\hline $\mathrm{Au} / \mathrm{ZrO}_{2}: \mathrm{Au} \mathrm{NC} / \mathrm{Pt}$ & $\sim 75$ & - & - & - & 51 & 1000 & Bipolar \\
\hline $\mathrm{TiN} / \mathrm{ZrO}_{2} / \mathrm{Pt}[28]^{\mathrm{a})}$ & - & Yes & - & - & 100 & - & Bipolar \\
\hline $\mathrm{TiN} / \mathrm{ZrO}_{2}: \mathrm{Al} / \mathrm{Pt}[28]^{\text {a) }}$ & - & No & $0.5-1.5$ & $-0.6--0.8$ & 100 & - & Bipolar \\
\hline $\mathrm{TiN} / \mathrm{HfO}_{2} / \mathrm{Pt}[25]^{\text {a) }}$ & - & - & $0.7-2.7$ & $-0.9--1.5$ & $\sim 3$ & - & Bipolar \\
\hline $\mathrm{TiN} / \mathrm{HfO}_{2}: \mathrm{Gd} / \mathrm{Pt}[25]$ & - & - & $0.8-1.0$ & $-0.6--0.9$ & $\sim 30$ & $10^{4}$ & Bipolar \\
\hline $\mathrm{Pt} / \mathrm{TiO}_{2} / \mathrm{Pt}[33]^{\mathrm{a})}$ & - & - & $0.25-1.75$ & $-0.25--0.5$ & 5 & 1000 & Bipolar \\
\hline $\mathrm{Pt} / \mathrm{TiO}_{2}: \mathrm{Pt} \mathrm{NC} / \mathrm{Pt}^{\text {a) }}$ & - & - & $0.5-1.0$ & $-0.5--0.75$ & 2 & $10^{4}$ & Bipolar \\
\hline $\mathrm{Cu} / \mathrm{NiO}_{x} / \mathrm{Pt}[34]^{\mathrm{a})}$ & - & Yes & $-2.6--8.6$ & $-1--1.8$ & 1000 & - & Unipolar \\
\hline $\mathrm{Cu} / \mathrm{Cu}: \mathrm{NiO}_{x} / \mathrm{Pt}^{\mathrm{a})}$ & - & No & $-2.1--3$ & $-0.6--1$ & $>10$ & - & Unipolar \\
\hline $\mathrm{W} / \mathrm{ZrO}_{2} / \mathrm{Pt}[35]^{\mathrm{a})}$ & 25 & - & - & - & - & - & Unipolar \\
\hline $\mathrm{W} / \mathrm{ZrO}_{2}: \mathrm{Ag} / \mathrm{Pt}^{\text {a) }}$ & 85 & Yes & - & - & 10 & - & Unipolar \\
\hline
\end{tabular}

a) Some data are taken from figures in references.

be greatly enhanced by implanting $\mathrm{Zr}$ ions [20].

\section{Conclusion}

The resistive switching characteristics of various devices using doping technology are summarized and shown in Table 1. Compared to an undoped device, the change induced by doping can be observed clearly. In summary, doping technology is an effective method for modulating and improving RRAM's performance. Generally, the doped BMO films exhibit many more preferred memory properties, including a free-electroforming process, low operation voltage, good electrical uniformity, and high device yield. To effectively improve the performance of the RRAM device by doping, more work needs to be done in understanding the physical mechanism and the inherent laws.

This work was supported by the National Basic Research Program of China (2010CB934200, 2008CB925002), the National Natural Science Foundation of China (60825403, 50972160) and the National HighTech Research \& Development Program of China (2008AA031403, 2009AA03Z306).

1 Meijer G I. Who wins the nonvolatile memory race? Science, 2008, 319: $1625-1626$

2 Baek I G, Lee M S, Seo S, et al. Highly scalable nonvolatile resistive memory using simple binary oxide driven by asymmetric unipolar voltage pulses. IEDM Tech Dig, 2004: 587-590

3 Waser R, Aono M. Nanoionics-based resistive switching memories. Nat Mater, 2007, 6: 833-840

4 Wang Y, Liu Q, Long S, et al. Investigation of resistive switching in $\mathrm{Cu}$-doped $\mathrm{HfO}_{2}$ thin film for multilevel non-volatile memory applications. Nanotechnology, 2010, 21: 045202

5 Yang Y C, Pan F, Liu Q, et al. Fully room-temperature-fabricated nonvolatile resistive memory for ultrafast and high-density memory application. Nano Lett, 2009, 9: 1636-1643

$6 \mathrm{Li} \mathrm{Y}$, Long S, Zhang M, et al. Resistive switching properties of $\mathrm{Au} / \mathrm{ZrO}_{2} / \mathrm{Pt}$ structure for low-voltage nonvolatile memory applications. IEEE Electron Device Lett, 2010, 31: 117-119

7 Xu N, Liu L, Sun X, et al. Characteristics and mechanism of conduction/set process in TiN/ZnO/Pt resistance switching random access memories. Appl Phys Lett, 2008, 92: 232112

8 Lee H Y, Chen P S, Wu T Y, et al. Low power and high speed bipolar switching with a thin reactive Ti buffer layer in robust $\mathrm{HfO}_{2}$ based RRAM. IEDM Tech Dig, 2008: 279-281

9 Guan W, Liu M, Long S, et al. On the resistive switching mechanisms of $\mathrm{Cu} / \mathrm{ZrO}_{2}: \mathrm{Cu} / \mathrm{Pt}$. Appl Phys Lett, 2008, 93: 223506

10 Wu L, Song Z, Liu B, et al. Remarkable resistance change in plasma oxidized $\mathrm{TiO}_{x} / \mathrm{TiN}_{x}$ film for memory application. Chin Phys Lett, 2007, 24: 1103-1105

11 Seo S, Lee M J, Seo D H, et al. Reproducible resistance switching in polycrystalline NiO films. Appl Phys Lett, 2004, 85: 5655

12 Sun X, Sun B, Liu L, et al. Resistive switching in $\mathrm{CeO}_{2}$ films for nonvolatile memory application. IEEE Electron Device Lett, 2009, 30: $334-336$

13 Banno N, Sakamoto I, Sunamura H, et al. Diffusivity of $\mathrm{Cu}$ ions in solid electrolyte and its effect on the performance of nanometer-scale switch. IEEE Trans Electron Device, 2008, 55: 3283-3287

14 Lv H, Wang M, Wan H, et al. Endurance enhancement of Cu-oxide based resistive switching memory with Al top electrode. Appl Phys Lett, 2009, 94: 213502

15 Li Y, Long S, Liu Q, et al. Nonvolatile multilevel memory effect in $\mathrm{Cu} / \mathrm{WO}_{3} / \mathrm{Pt}$ device structures. Phys Status Solidi RRL, 2010, 4: $124-126$

16 Guan W, Long S, Jia R, et al. Nonvolatile resistive switching memory utilizing gold nanocrystals embedded in zirconium oxide. Appl Phys Lett, 2007, 91: 062111

17 Liu Q, Long S B, Wang W, et al. Low-power and highly uniform switching in $\mathrm{ZrO}_{2}$-based ReRAM with a $\mathrm{Cu}$ nanocrystal insertion layer. IEEE Electron Device Lett, 2010, 31: 1299-1301

18 Liu Q, Long S, Lv H, et al. Controllable growth of nanoscale conductive filaments in solid-electrolyte-based ReRAM by using a metal nanocrystal covered bottom electrode. ACS Nano, 2010, 4: 61626168

19 Yoon J H, Kim K M, Lee M H, et al. Role of Ru nano-dots embedded 
in $\mathrm{TiO}_{2}$ thin films for improving the resistive switching behavior. Appl Phys Lett, 2010, 97: 232904

20 Liu Q, Guan W H, Long S B, et al. Resistive switching memory effect of $\mathrm{ZrO}_{2}$ films with $\mathrm{Zr}^{+}$implanted. Appl Phys Lett, 2008, 92: 012117

21 Wong M F, Herng T S, Zhang Z, et al. Stable bipolar surface potential behavior of copper-doped zinc oxide films studied by Kelvin probe force microscopy. Appl Phys Lett, 2010, 97: 232103

22 Liu Q, Guan W H, Long S B, et al. Resistive switching of Auimplanted- $\mathrm{ZrO}_{2}$ film for nonvolatile memory application. J Appl Phys, 2008, 104: 114514

23 Guan W, Long S, Liu Q, et al. Nonpolar nonvolatile resistive switching in $\mathrm{Cu}$ doped $\mathrm{ZrO}_{2}$. IEEE Electron Device Lett, 2008, 29: 434-437

24 Liu Q, Long S B, Wang W, et al. Improvement of resistive switching properties in $\mathrm{ZrO}_{2}$-based ReRAM with implanted Ti ions. IEEE Electron Device Lett, 2009, 30: 1335-1337

25 Zhang H, Liu L, Gao B, et al. Gd-doping effect on performance of $\mathrm{HfO}_{2}$ based resistive switching memory devices using implantation approach. Appl Phys Lett, 2011, 98: 042105

26 Zhang $\mathrm{H}$, Gao B, Sun B, et al. Ionic doping effect in $\mathrm{ZrO}_{2}$ resistive switching memory. Appl Phys Lett, 2011, 96: 123502

27 Dearnaley G, Stoneham A M, Morgan D V. Electrical phenomena in amorphous oxide films. Rep Prog Phys, 1970, 33:1129

28 Gao B, Zhang H, Yu S, et al. Oxide-based RRAM: Uniformity im- provement using a new material-oriented methodology. VLSI Tech Dig, 2009: 30-31

29 Lee D, Seong D, Choi H, et al. Excellent uniformity and reproducible resistance switching characteristics of doped binary metal oxides for non-volatile resistance memory applications. IEDM Tech Dig, 2006: 797

30 Jung K, Choi J, Kim Y, et al. Resistance switching characteristics in Li-doped NiO. J Appl Phys, 2008, 103: 034504

31 Wang M, Luo W J, Wang Y, et al. A novel $\mathrm{Cu}_{x} \mathrm{Si}_{y} \mathrm{O}$ resistive memory in logic technology with excellent data retention and resistance distribution for embedded applications. VLSI Tech Dig, 2010: 89-90

32 Liu Q, Liu M, Long S B, et al. Improvement of resistive switching properties in $\mathrm{ZrO}_{2}$-based ReRAM with implanted metal ions. In: Proceeding of the European Solid-State Device Research Conference, 2009 Sep 14-18, Athens. 221-224

33 Chang W, Cheng K, Tsai J, et al. Improvement of resistive switching characteristics in $\mathrm{TiO}_{2}$ thin films with embedded Pt nanocrystals. Appl Phys Lett, 2009, 95: 042104

34 Liu C, Lin X, Wang H, et al. Improved resistive switching dispersion of $\mathrm{NiO}_{x}$ thin film by Cu-doping method. Jpn Appl Phys Lett, 2010, 49: 056507

35 Sun B, Liu L, Han D, et al. Improved resistive switching characteristics of $\mathrm{Ag}$-doped $\mathrm{ZrO}_{2}$ films fabricated by sol-gel process. Chin Phys Lett, 2008, 25: 2

Open Access This article is distributed under the terms of the Creative Commons Attribution License which permits any use, distribution, and reproduction in any medium, provided the original author(s) and source are credited. 